\title{
Oral and dental aspects of child abuse
}

\author{
Arlétte Suzy Puspa Pertiwi and Inne Suherna Sasmita \\ Pedodontics Department \\ Faculty of Dentistry Padjajaran University \\ Bandung - Indonesia
}

\begin{abstract}
Child abuse is defined as those acts or omissions of care that deprive a child from the opportunity to fully develop his or her unique potentials as a person either physically, socially or emotionally. The overall incidence of child abuse is not really clear. Statistical data do not show the actual rate because of the unreported cases. Dentists are in a strategic position to recognize and report the children being abused because they often see the child and parents interacting during multiple visits and over a long period of time. The orofacial region is commonly traumatized during episodes of child abuse. The characteristics and diagnostic finding of child abuse, and the protocol of reporting such cases, should be familiar to the dentist so that appropriate notification, treatment and prevention of further injury can be instituted. Dentists with experience or expertise in child abuse and neglect will strengthen their ability to prevent and detect child abuse and neglect and enhance the ability to care for and protect children. This paper discusses the oral and dental aspects of child abuse and the dentist role in evaluating this situation including prevention of child abuse.
\end{abstract}

Key words: child abuse, oral and dental aspects

Correspondence: Arlétte Suzy Puspa Pertiwi, c/o: Bagian Pedodonsia, Fakultas Kedokteran Gigi Universitas Padjadjaran. Jln. Sekeloa Selatan I Bandung 40135, Indonesia. E-mail: arlettesuzy@ yahoo.com

\section{INTRODUCTION}

Recently, the cases of child abuse often appear either the ones with the family member as the actor or other party. In medical field, child abuse (CA) was reported at the first time in 1860 in France when 320 children died of the causes suspected as abuse. ${ }^{1}$

Child abuse is defined as those acts or omissions of care that deprive a child from the opportunity to fully develop his or her unique potentials as a person either physically, socially or emotionally. ${ }^{2}$ Child abuse is not limited to certain social class in a society. In the middle- to lower-class society, many CA are often caused by poverty. Meanwhile, in the middle- to upper- class society, CA is often caused by the parents' ambition to shape the children according to their ideals about the best thing for them. Generally there are five factors that trigger CA, namely moral degradation, abnormal nurturing pattern, media exposure, low level of economy, and low level of education. $^{3}$

There are 4 major types of CA, physical abuse, sexual abuse, emotional abuse, and neglect. There are also other types of CA including child exploitation or employing children under age for commercial purpose while pushing aside the child's physical, mental, and social development. ${ }^{4}$

There is no well-known data on the incidence of CA. The statistical data does not show the actual numbers of cases because there are a lot of cases go unnoticed..$^{5}$ In Indonesia, based on the data of Children National Commission, there are 544 cases of CA in 2004 and increasing into 736 of cases in 2005., 3 Until mid-January of 2006, there have been 4 cases found on child abuse. ${ }^{7}$

Some countries have legal regulation that defines legal obligation to report to the local child protection institution if there is any suspicion towards CA. The persons who have the authority to report the case includes doctors and dentists. ${ }^{1}$ Dentist has a strategic position to identify and report children who experienced CA since he/she often observes interaction between children and parents/caregiver during treatment visit and in a long period of time. ${ }^{2}$ This paper describes oral and dental aspects of CA and the dentist role in evaluating the situation.

\section{Physical abuse}

Physical abuse is a physical injury experienced by children, which is not caused by accidents. ${ }^{4}$ Craniofacial, facial, head and neck injuries are found in more than a half of CA cases. Careful intraoral and perioral examination is needed in every suspect of CA. ${ }^{8}$ Oral cavity and orofacial region often becomes the main focus of physical abuse because of their functions in communication and nutrition. ${ }^{2,8}$ A complete examination on oropharynx must include examination on frenulum, gingival, soft and hard palate, tongue, sublingual region, buccal mucosa and posterior pharynx to observe every signs of trauma. ${ }^{9}$

Dental practioners are able to identify physical evidence of injuries to children, especially in the regions of the head and neck and oro-facial structures. When such injuries are of suspicious origin, the dentist has an obligation to document and report his/her findings to appropriate 
authorities so that proper action may be taken to protect the child while the problem is investigated. ${ }^{10}$

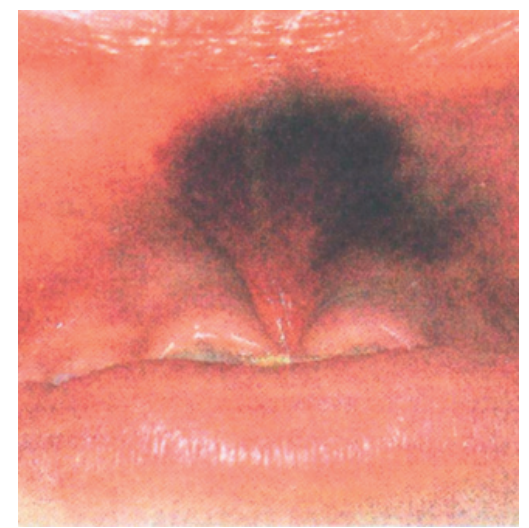

Figure 1. Bruise on frenulum caused by blows on the face ${ }^{2}$

Injury in oral cavity is commonly caused by blunt trauma, such as trauma caused by tableware, hand, fingers, blunt instruments or caustic substance. The violence can caused contusion, laceration and bruise on the tongue, buccal mucosa, palate, gingival mucosa or frenulum, dental or avulsion fracture, facial and jaw fracture, burn, and other kinds of injuries (Figure 1). Besides, trauma in oral cavity, tongue, palate and frenulum, blunt trauma on the teeth and facial bone and jaw bone fracture can be caused by repetitive trauma. ${ }^{9}$ Discoloration of the teeth, besides the abovementioned injuries, also shows the existence of pulp necrosis that can be caused by previous trauma. ${ }^{8}$ Wound, bleeding, erythema, or swollen outer ear canal, broken lips, unstable teeth or fractured teeth, tongue laceration and blue eyes without trauma on the nose indicates physical abuse. ${ }^{1}$

\section{Sexual abuse}

Sexual abuse is every sexual act between older person and the child. The acts can be called sexual abuse if the one who does the act is the caregiver, family members, father, mother, nanny, or teacher, either at home or outside the child's house. If a stranger performs that kind of action, the action is called sexual assault. ${ }^{4}$

Oral cavity is one of the locations of sexual abuse often found in children. The existence of gonorrhea or syphilis in the oral or perioral region in prepubertal children is one of the signs of sexual abuse. Cement detection in the child's oral cavity can be performed in a few days period after the abuse. Therefore, during an investigation towards a child who is suspected as a victim of sexual abuse, cotton swab should be performed to get the buccal mucosa and tongue smear. ${ }^{8}$ Erythema or petechiae palatum, especially in the junction between soft and hard palate can become a proof of forced oral sex action (Figure 2). Another oral lesion can be found in the form of condylomata acuminata. ${ }^{8}$

Bite marks can be a lesion that leads to abuse acts (Figure 3-a and b). Bite marks are one of several visual expressions of active child abuse. ${ }^{9}$ The dentist should be

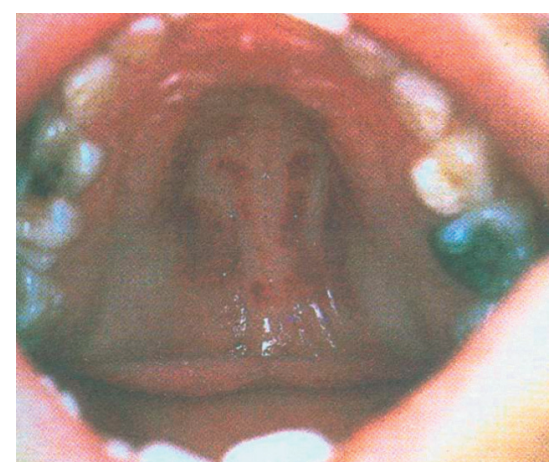

Figure 2. Injuries caused by sexual assault ${ }^{2}$

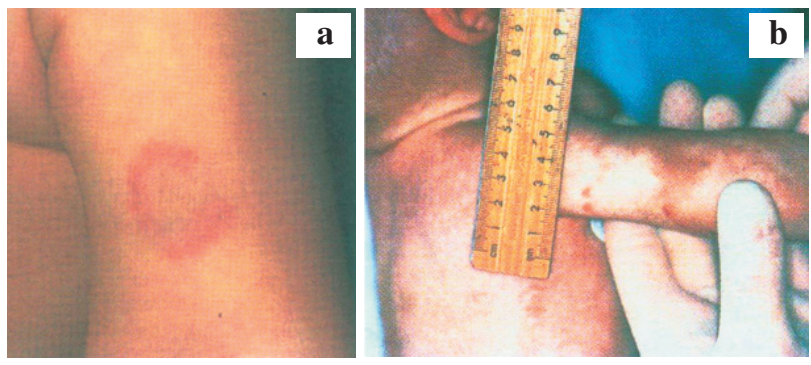

Figure 3. a) Bite marks on 18 month old child and b) Three month old baby ${ }^{2}$

able to play the role of forensic odontologist in order to detect and evaluate bite marks. The lesion, besides being caused by sexual abuse, can also be caused by physical abuse. Bite marks should be suspected as the signs of echymoses, abrasion, or laceration in elliptical or ovoid patterns. Bite marks can be in the form of echymoses in the middle area that can be caused by 2 possibilities, positive pressure of teeth grinding with disturbance in the small vessels and negative pressure caused by tongue sucking. ${ }^{8}$

We should be able to tell the different between bite marks caused by a human being or caused by animal bites. Animal bites, such as dog, tend to create an open wound while human bite marks tend to be wound caused by pressure, such as abrasion, contusion, and laceration. The spacing in human bites is normally 2.5 to $4 \mathrm{~cm}$, which is the distance between the upper canines. If the intercanines distance is less than $2.5 \mathrm{~cm}$, the big chance is that the bite is caused by children. If the distance is 2.5 to $3 \mathrm{~cm}$, the bite is caused by a teenager, and if it's more than $3 \mathrm{~cm}$, it is caused by an adult bite. 8

\section{Emotional abuse}

Emotional abuse is defined as every attitudes or behaviors that can disturb mental health or social development of a child. Other names for emotional abuse are verbal abuse, mental abuse, or psychological maltreatment. Emotional abuse almost always happens together with other forms of abuse. ${ }^{3}$

Emotional abuse does not leave trauma signs on the child's body, but it leaves psychological trauma on the child. The children become scared of everything, apathetic, 
depressed, experience concentration disorders, or rebellions. If this situation keeps going on, it can create serious behavior disorders, cognitive disorders, emotional or mental disorders for the children. Dentist should be able to recognize signs in children who is the victim of emotional abuse and apply appropriate new approaches. ${ }^{3}$

\section{Neglect}

Neglect is an ignorance towards the child either in the form of nurturing, supervising, care, and education that can caused destructive effect on the child's physical condition and his/her psychological development. ${ }^{1}$ There are 3 types of neglects; physically neglect, educationally neglect, and emotionally neglect. ${ }^{3}$ In the dentistry area, a dental neglect is also recognized as a part of physically neglect. 8

Dental neglect, as defined by American Academy of Pediatric Dentistry, is intentional neglect by the parents or caregiver towards the child's oral cavity and dental health or a neglect that prevent the child to get dental and oral treatment needed by the child in order to achieve oral health level needed for adequate function. ${ }^{8}$ Dental neglect can be seen as the appearance of caries, periodontal disease, and other oral cavity diseases. 8,10

Caries, periodontal diseases and other oral condition, if not treated, can lead to pain, infection, and loss of oral function that can affect communication, nutrition, learning activities and other children activities needed for normal growth and development. ${ }^{8}$ Failure to get good dental treatment can be caused by various factors such as family isolation, poor financial status, parent's neglect and lack of appreciation towards oral health value. The point at which to consider a parent negligent and to begin intervention occurs after the parent has been properly alerted by a health care professional about the nature and extent of the child's condition, the specific treatment needed, and the mechanism of accessing that treatment. ${ }^{8}$

The dentist should be certain that the caregivers understand the explanation of the disease and its implications and, when barriers to the needed care exist, attempt to assist the families in finding financial aid, transportation, or public facilities for needed service. Parent is should be reassured that appropriate analgesic and anesthetic procedures will be used to assure the child's comfort during dental procedures. If, despite these efforts the parent is fail to obtain therapy, the case should be reported to appropriate child protective services. ${ }^{11}$

\section{Prevention of child abuse}

Children are a nation's next generation. Therefore, CA should be prevented because it can affect the long life process of a child. ${ }^{1}$ In Indonesia, dentist's authority to report $\mathrm{CA}$ has not been regulated in a law or regulation. However, prevention and management of abuse and violence towards children is a serious matter that should be acted on immediately by all related parties, including the parents, educators, law force, security force, mass media and health service. $^{1}$

\section{DISCUSSION}

Child abuse is both shocking and commonplace. Child abuses inflict physical, sexual, and emotional trauma on defenseless children every day. The scars can be deep and long lasting. Unfortunately, the more subtle forms of child abuse such as neglect and emotional, it can traumatize the child as deep as violent physical abuse. Focused support can help both victims of CA and the abusers.

The effects of abuse and neglect depend on some factors. First, the age of the child when the abuse was happen. The younger child usually the harmful effect will occur, but different effects are associated with different developmental periods. Second, who committed the abuse? Effects are generally worse when it was the parent, stepparent or trusted adult than a stranger. Third, has the child told anyone, and if so, the response of the person on the child's story will give effects. Doubting, ignoring, blaming and shaming responses can be extremely harmful - in some cases even more than the abuse itself. Fourth, was violence involved, and if so, how severe. Fifth, how long the abuse went on.

Child abuse and dentistry have a close correlation because of three possible reasons. Sixty five percent of injuries resulting from child abuse are on the head, neck, or mouth. The victims may avoid the same physician, but return to the same dentist. Children are most likely to have regular preventive care in the same dental office. ${ }^{8,9}$

According to Needleman, 1986, studies demonstrate that trauma to the head and associated areas occurs approximately $50 \%$ of the cases of physical abuse to children. Soft tissue injuries, most frequent bruises, are the most common injury sustained to the head and face and are the single most common injury sustained in child abuse. Injuries to the upper lip and maxillary labial frenum may be characteristic lesion in the severely abused young child. ${ }^{12}$

Suspected abuse can be documented because of the trauma associated with burning, slapping, hitting, choking, pulling or pinching. Broken teeth, burns, lacerations, bruises and broken bones could alert the dentist that something wrong had happened on the child. Neglect, however, is more subtle. The dentist should look at overall hygiene as well as dental hygiene and adequacy of clothing. Suspicion of poor nutrition, apparent lack of medical care, and absence of previous dental care are situations that should alert the dentist to consider neglect.

The American Academy of Pediatric Dentistry defines dental neglect as failure of the parent or guardian to seek treatment for caries, oral infection, or oral pain, or failure of the parent or guardian to follow through with treatment once he or she is informed that the aforementioned conditions exist. Thus the guidelines of dental neglect are untreated rampant caries; untreated pain, infection, bleeding, or trauma; and lack of continuity of care once informed that above conditions exist.

In foreign countries, physicians and dentists realize their responsibility to report suspected cases of CA. In US, they 
are required to report it to social service or law enforcement agencies. ${ }^{13}$ Physicians receive minimal training in oral health and dental injury and dental disease, thus may not detect dental aspects of CA like they do on CA involving other areas of the body. Therefore, physicians and dentists should collaborate to increase the prevention, detection, and treatment of this conditions. ${ }^{14,15,16}$ In Indonesia, there is no such action yet. The dentist knowledge and skill in managing CA has not been fully gained. Therefore, CA and forensic dentistry curriculum should get a place in the education program.

Child abuse (CA) consists of all bad treatments acted on a child by the parents, caregivers or other person/s who should be giving care and security for the children. CA can be found in all social classes and can be caused by various triggers. The long-term effects of chronic exposure to domestic violence and CA may affect a child's overall development. Social, cognitive, and emotional development may be adversely affected.

The study suggest that dentist has a role in identifying, managing, helping and treating $\mathrm{CA}$ victims since the injuries are often found in the oral and facial areas. Besides managing such cases, dentist also has a role in preventing CA because the CA can affect the future life of the children. Such efforts will enhance the ability to care and protect children.

\section{REFERENCES}

1. Sitohang NA. Asuhan keperawatan pada anak child abuse. Medan: USU Digital Library; 2004. h. 1-6. Available at: www.library.usu.ac.id. Accessed February 23, 2006.
2. Cameron A. Trauma management. In: Cameron AC, editor. Handbook of pediatric dentistry. $2^{\text {nd }}$ ed. Sydney: Mosby; 2003. p. 88-90.

3. Sucahyani BD. Kekerasan pada anak. Batam: Batam Pos, 22 nd January 2006. Available at: www.batampos.com. Accessed February 19, 2006.

4. de Benedictis T, Jaffe J, Segal J. Child abuse: types, signs, symptoms, causes and help. Available at www.helpguide.org. Accessed February $25,2006$.

5. Hopper J. Child abuse, statistic, research, and resources. Available at: www.jimhopper.or.id. Accessed February 19, 2006.

6. Sofiyan I. PKK harus mengajak masyarakat terus berkiprah. Available at: www.kotabogoronline.htm. Accessed February 19, 2006.

7. Data Statistik Kekerasan Pada Anak. Available at: www.pdpersi.co.id. Accessed February 19, 2006.

8. Kellog N. Oral and dental aspects of child abuse and neglect. Pediatrics 2005; 116:1565-8.

9. Jessee S. Recognition of bite marks in child abuse cases. AAPD Journal 1994; 16:336-9.

10. Sirotnak AP, Grigsby T. Physical abuse of children. Pediatrics in Review 2004; 25: 264-77.

11. Croll TP, Menna VJ, Evans CA. Primary identification of an abused child in a dental office. American Academy of Pediatric Dentistry Journal 1981; 3:339-42.

12. Needleman HL. Orofacial trauma in child abuse: types, prevalence, management and the dental prefession's involvement. Pediatr Dent 1986; 8:71-80.

13. Sanger RG, Bross DC. Clinical management of child abuse and neglect: A guide for the dental professional. Chicago: Quintessence Publishing Co, Inc; 1984. p. 37-46.

14. Mouden LD, Bross DC. Legal issues affecting dentistry's role in preventing child abuse and neglect. Journal of American Dentistry Association 1995; 126:1173-80.

15. Schwartz S, Woolridge E, Stege D. The role of the dentist in child abuse. Quintessence Int 1997; 7:79-81.

16. Donly KJ, Nowak AJ. Maxillofacial, neck, and dental lesions of child abuse. In: Reece, RM, editor. Child abuse: Medical diagnosis and management. Philadelphia: Lea \& Febiger; 1994. p. 211-51. 